\title{
Interannual variability of the North Pacific Subtropical Countercurrent: Role of local ocean-atmosphere interaction
}

\author{
Fumiaki Kobashi ${ }^{1,2}$ and Shang-Ping $\mathrm{Xie}^{3}$
}

\author{
${ }^{1}$ Faculty of Marine Technology, Tokyo University of Marine Science and Technology, Tokyo, Japan \\ ${ }^{2}$ Research Institute for Global Change, Japan Agency for Marine-Earth Science and Technology, Yokosuka, Japan \\ ${ }^{3}$ International Pacific Research Center and Department of Meteorology, University of Hawaii, Honolulu, USA
}

Submitted on 5 January 2011

Revised on 17 May 2011

To Journal of Oceanography

Corresponding author: Fumiaki Kobashi, e-mail: kobashi@kaiyodai.ac.jp

Tokyo University of Marine Science and Technology, Faculty of Marine Technology

Etchujima 2-1-6, Koto-ku, Tokyo 135-8533, JAPAN 


\section{Abstract}

Seasonal and interannual variability of the Subtropical Countercurrent (STCC) in the western North Pacific are investigated using observations by satellites and Argo profiling floats and an atmospheric reanalysis. The STCC displays a clear seasonal cycle. It is strong in late winter to spring with a peak in June, and weak in fall. Interannual variations of the spring STCC are associated with an enhanced subtropical front (STF) below the surface mixed layer. In climatology, the SST front induces a band of cyclonic wind stress in May north of the STCC on the background of anticyclonic curls that drive the subtropical gyre. The band of cyclonic wind and the SST front show large interannual variability and are positively correlated with each other, suggesting a positive feedback between them. The cyclonic wind anomaly is negatively correlated with the SSH and SST below. The strong (weak) cyclonic wind anomaly elevates (depresses) the thermocline and causes the fall (rise) in the SSH and SST, accelerating (decelerating) STCC to the south. It is suggested that the anomalies in the SST front and STCC in the preceding winter affect the subsequent development of the cyclonic wind anomaly in May. Results from our analysis of interannual variability support the idea that the local wind forcing in May causes the subsequent variations in STCC. 


\section{Introduction}

The Subtropical Countercurrent (STCC) flows eastward in the southern subtropical gyre of the North Pacific where the classical wind-driven circulation theory predicts a broad westward flow. The STCC accompanies a subsurface temperature and density front called the subtropical front (STF; Uda and Hasunuma 1969). Figure 1 shows the temperature section along $155^{\circ} \mathrm{E}$ from the World Ocean Circulation Experiment (WOCE) Hydrographic Program (WHP), displaying two subsurface STFs which are associated with a northward shoaling of the upper main thermocline. Below the upper thermocline, mode water, a vertically homogeneous water mass characterized by low potential vorticity (PV), exists to the north of the STF.

Recent studies show that mode water plays a central role in the STCC and STF formation. Using an idealized ocean general circulation model (GCM), Kubokawa and Inui (1999) reproduced STCC on the southern flank of low PV water in the thermocline. In their model, the low PV water originates in the deep surface mixed layer in the northwestern subtropical gyre and is subducted at the intersection of the density outcrop line and a mixed layer depth (MLD) front. The MLD front is a narrow transition zone separating shallow and deep mixed layers. The low PV waters subducted on different isopycnals from different locations are advected southward by the subtropical gyre, eventually stacked up in the vertical and forming a thick low-PV pool. This thick low-PV pool causes the upper pycnocline to rise, forming a density front and eastward countercurrent on the southern edge of the low-PV pool. The ventilated thermocline affected by the MLD front and the resultant STCC formation are theoretically discussed by Kubokawa (1999). This mechanism has won support from observations (Aoki et al. 2002; Kobashi et al. 2006). Constructing a long-term mean climatology from enhanced hydrographic data, Kobashi et al. (2006) found double bands of STCC extending almost zonally along $19-21^{\circ} \mathrm{N}$ and $21-26^{\circ} \mathrm{N}$ (Fig. 2), and showed that these two bands are each anchored by mode waters below the STF to the north. They indicated the importance of the Subtropical Mode Water (STMW; Masuzawa 1969) and the 
Central Mode Water (CMW; Nakamura 1996; Suga et al. 1997) in the formation of STCC.

The STCC is maintained not only by the subsurface front but also partly by a surface front. Along the northern STCC in the western Pacific, the surface front appears with a distinct sea surface temperature (SST) front during winter and early spring (Kobashi and Kawamura 2002). A recent finding is that the SST front of the northern STCC significantly influences on the overlying atmosphere. From an analysis of satellite observations and an atmospheric reanalysis, Kobashi et al. (2008) found that, in April to May along the SST front surface, wind stress curls turn weakly cyclonic on the general background of anticyclonic curls that drive the subtropical gyre. The cyclonic wind curls are collocated with a band of high column water vapor, indicative of a deep structure of the moist layer. On the weather timescale, the cyclonic curls are associated with low pressure systems of a subsynoptic scale in space, fueled by atmospheric baroclinicity due to the SST front and latent heat release associated with high SST in April to May. Similar atmospheric effects are observed from coupled GCM simulations, where SST anomalies created by thermal advection of the STCC causes cyclonic surface wind curls and local maximum of precipitation along the STCC (Tokinaga et al. 2009; Xie et al. 2011).

The STCC exhibits variability on various timescales. Analyzing historical temperature profiles in the western North Pacific, White et al. (1978) found seasonal and interannual variations of STF. On the seasonal timescale, the STF is strong in spring and weak in fall. This seasonal cycle has been confirmed by Kobashi and Kawamura (2002) using updated hydrographic observations. They showed that the STCC is clearly identified in winter to summer with the strongest subsurface STF in spring. The mechanism for the seasonal variations in the subsurface STF has not been clarified yet.

Interannual variations of STCC and STF have not been examined since the study of White et al. (1978). Recently Qiu and Chen (2010) found interannual changes in mesoscale eddy variability in the western STCC region, where enhanced eddy production occurs through baroclinic 
instability of the vertically sheared current system between the STCC and underlying wind-driven westward flow (Qiu 1999; Kobashi and Kawamura 2002). Analyzing repeat hydrographic surveys across the STCC along the $137^{\circ} \mathrm{E}$ meridian, which is conducted seasonally by the Japan Meteorological Agency (JMA), they showed that the vertical shear of STCC tends to be larger in eddy-rich years than in eddy-weak years, indicating that the intensity of baroclinic instability controls the interannual changes in the eddy activity. Furthermore, they showed a correlation between the eddy activity and the meridional Ekman convergence associated with basin-scale surface winds, suggesting that the Ekman convergence affects surface temperature frontogenesis along the STCC, causing the changes in the vertical shear of the STCC and thus the eddy activity. Their results indicate the Ekman convergence as a cause of interannual variations in the STCC.

Recent numerical modeling studies have revealed STCC variability induced by mode waters (Yamanaka et al. 2008; Nonaka et al. 2011). Analyzing long hindcasts using realistic eddy-resolving ocean GCMs, Yamanaka et al. (2008) showed that the intensity of STF is strong in the late 1970s and weak in the early 1990s. This decadal variability is caused by changes in strength and path of STMW and CMW in the model. The advection of lower-PV mode waters strengthens the STF, while the weak intensity and reduced southward intrusion of mode water result in the weak STF. A similar effect of mode water on surface circulation is also reported from Argo observations on the Hawaiian Lee Countercurrent by Sasaki et al. (2011). The mode-water induced STCC variability is also found in coupled GCM simulations, in which decadal variability of mode water ventilation, in particular CMW ventilation, alters the STCC and its thermal advection, inducing SST and atmospheric response (Xie et al. 2011). Such climate effects of mode water ventilation are found with distinct spatial patterns of SST changes in global warming simulations (Xie et al. 2010; Xu et al. 2011). For details on the changes in the STCC and their relation to mode waters, see the review paper by Kobashi and Kubokawa (2011).

The present study examines seasonal and interannual variations of the northern STCC in the 
western Pacific, using observations from satellites and Argo profiling floats and an atmospheric reanalysis. We show that local cyclonic wind curl in May induced by the SST front is a primary cause of interannual variations in the STCC in spring. In a mean state, the northern STCC is maintained by the low PV core of the STMW (Kobashi et al. 2006), which is indentified to the north of the STF as a thermostad of about $17^{\circ} \mathrm{C}$ in Fig. 1. We find no significant correspondence between the variations of the spring STCC and STMW on interannual timescales.

The remainder of the paper is organized as follows. Section 2 describes the data used in this study. Section 3 investigates the seasonal variations of the STCC, the SST front and the wind stress curl. Section 4 examines the characteristics of interannual variations of the STCC, and then links the STCC variations to local wind curl changes. Section 4 is a summary and discusses the implications of this study.

\section{Data}

To examine STCC variability, we use a satellite altimetry product, the Maps of Absolute Dynamic Topography from 1993 to 2008, from Archiving, Validation and Interpretation of Satellite Oceanographic data (AVISO), France. The sea surface height (SSH) observed from multiple satellites is merged and mapped onto a $1 / 3^{\circ}$ Mercator grid every 7 days. We use homogenous dataset based on stable sampling of $\mathrm{SSH}$ in time, which is constructed from the observations of two satellites (Topex/Poseidon and European Remote Sensing satellites or Jason-1 and Envisat or Jason-2 and Envisat) with the same ground track.

An optimally interpolated SST dataset developed by the National Climatic Data Center (NCDC) of the National Oceanic and Atmospheric Administration (NOAA) is used to explore the SST front. This dataset is produced from the blend of Advanced Very High Resolution Radiometer (AVHRR) infrared satellite observations and in-situ measurements and is processed onto daily 
SST maps on a $0.25^{\circ}$ grid (Reynolds et al. 2007). We analyze the data from 1982 to 2008 .

We use the Japanese 25-year Reanalysis (JRA-25), which is produced by JMA and Central Research Institute of Electric Power Industry (CRIEPI). The JRA-25 is computed on a T106 global spectral forecast model with 40 vertical levels using a three dimensional variational data assimilation method (Onogi et al. 2007). The JRA-25 data cover a period from 1979 to 2004, and the data since 2005 are continually computed using the real-time climatic assimilation system named JMA Climate Data Assimilation System (JCDAS), the same as the JRA-25 data. We use 6-hourly surface wind stress vectors on a T106 Gaussian grid (approximately $1.125^{\circ}$ grid) for the period from 1982 to 2008 .

Temperature data obtained by Argo profiling floats are used to investigate ocean structures in the STCC region. The dataset is based on Argo's real-time quality controlled data archived by the Argo Global Data Assembly Center, which are further processed with visual inspection for suspect data by Oka et al. (2007). We also use Grid Point Value of the Monthly Objective Analysis using the Argo data (MOAA GPV) produced by Hosoda et al. (2008), where temperature and salinity profiles from real-time quality controlled Argo data and available ship observations are optimally interpolated at standard depths on a $1^{\circ}$ grid in space every month since 2001 . This data is spatially smoothed, but it can be used to examine changes in mode water broadly distributed to the north of the STCC.

\section{Seasonal variability}

The monthly climatology maps of SST, meridional SST gradient, wind stress, wind stress curl and surface geostrophic velocity are calculated from the data from 1993 to 2008 . The meridional SST gradient is used to track SST fronts. Since the SST front in the STCC region extends almost zonally, the meridional gradient represents well the strength of the SST front. Surface geostrophic 
velocity is obtained from absolute SSH maps assuming geostrophy. Figure 3 shows the meridional profiles of these variables zonally averaged between $135^{\circ}$ and $150^{\circ} \mathrm{E}$. This longitude range corresponds to the area with pronounced cyclonic wind curls induced by the STF (Kobashi et al. 2008).

Figure $3 \mathrm{c}$ shows two distinct bands of an eastward flow in the latitude ranges of $18^{\circ}-19^{\circ} \mathrm{N}$ and $20^{\circ}-26^{\circ} \mathrm{N}$. The meridional positions of these two bands are consistent with the hydrographic observations in Fig. 2, and they are referred to as the southern and northern STCCs by Kobashi et al. (2006). The eastward velocity of the northern STCC becomes strong in late winter to spring with the peak in June, and becomes weak in fall, in agreement with the result of hydrographic observations by Kobashi and Kawamura (2002). The change in the meridional velocity is smaller than in the zonal velocity, but there is an identifiable tendency for the STCC to flow southward in spring to summer (see vectors in Fig 3c).

Seasonal variation is also evident along the southern STCC, where the STCC appears with eastward velocity in spring to summer. In winter and fall, though no eastward current, there is a meridional minimum in westward velocity at almost the same position of the southern STCC. The STF leaves clear signature in the annual mean map of surface velocity relative to $400 \mathrm{dbar}$ (Fig. 2) that represents the vertically integrated strength of STF. The absolute surface velocity in Fig. 3c reflects density structure integrated over the whole water depth. The lower thermocline below the STF deepens toward the north (Fig. 1), opposing the effect of the STF on the surface velocity field through the thermal wind relation. Thus, the weak STF does not result in an eastward current at the surface. This study focuses on the northern STCC.

The SST front appears in late fall to the following spring between $24^{\circ}$ and $28^{\circ} \mathrm{N}$. In January to April, the SST front is nearly collocated with the STCC along $24.5^{\circ} \mathrm{N}$, but in May and June the SST front moves north, while the STCC is slightly shifted to the south. The separation of the SST front from the STCC is also identified from the hydrographic section in Fig. 1, where the SST 
front is found around $26^{\circ} \mathrm{N}$, located further north of the subsurface STF associated with the STCC. The seasonal cycle of the SST front agrees with the results of Kobashi et al. (2008) based on satellite microwave measurements.

Atmospheric effects of the SST front are obvious in the JRA wind stress curl (Fig. 3b). Consistent with the satellite observations of Kobashi et al. (2008), the negative anticyclonic curl over the subtropical gyre decreases locally to the south of the SST front in April to May, indicating cyclonic wind stress curl anomaly induced by the SST front. This cyclonic wind anomaly seems to be followed by the intensification of the STCC in May to June to the south of the cyclonic curl, suggesting that the wind curls in spring have something to do with the subsequent intensification of the STCC. This hypothesis will be tested in Section 4 by focusing on interannual variations of the STCC.

The STCC speed is related to both the surface and subsurface STFs. We estimate the contributions of these two fronts, to infer the mechanism for the seasonal variation. The monthly-mean STCC velocity is extracted as a meridional maximum between $20^{\circ}$ and $26^{\circ} \mathrm{N}$ in Fig. 3c, plotted for each month in Fig. 4, together with the 90\% confidence interval of the zonal mean. The confidence interval is estimated based on a degree of freedom that is calculated from the spatial correlation function used in the mapping procedure of the SSH (Le Trano et al. 1998). From the thermal wind relation, the vertical shear of zonal geostrophic velocity within the surface mixed layer $\Delta u$ is related to the meridional gradient of temperature $\partial T / \partial y$, as expressed by

$$
\Delta u=-\alpha g h(\partial T / \partial y)
$$

where $\alpha$ is the thermal expansion coefficient, $g$ is the gravity constant and $h$ is the MLD. This study calculated the temperature gradient from the mean meridional profile of the SST in Fig. 3a and used the value at the STCC position. The thermal expansion coefficient was computed using the SST at the STCC position in Fig. 3a and constant salinity (=35). Since this coefficient is almost constant throughout a year, it affects little seasonal changes in the vertical shear. The MLD was 
estimated from the monthly climatology based on Argo observations (Ohno et al. 2009). Averaging the data zonally between $135^{\circ}$ and $150^{\circ} \mathrm{E}$, we used the value of the MLD at the STCC position. Figure 4 shows the STCC velocity minus the $\Delta u$, which represents the effect of the subsurface front below the mixed layer.

In November to February, the surface front accounts for the most part of the STCC, explaining about $70 \%$ on average. This is due to the formation of a relatively strong surface front (Fig. 3a) within the deep mixed layer. In March and April, although the mixed layer becomes shallower in the STCC region as reported by Takeuchi and Yasuda (2003), the strong surface front (Fig. 3a) makes a significant contribution to the STCC strength (about 30\%). From May to October, the STCC is almost maintained by the subsurface front.

\section{Interannual variability}

The analysis on the seasonal cycle suggests that the wind curls in spring induced by the SST front have some relation to the subsequent variations of the STCC. In this section we test this hypothesis by examining interannual variability.

Before taking a look at the relation between the STCC and the wind stress curl, we describe how the interannual variations of the STCC in each month are related to those in other months, with a focus on late winter to spring when the STCC is strong. For this purpose, the interannual time series of the STCC velocity is made for each month, by averaging the zonally-averaged zonal geostrophic velocity between $135^{\circ}$ and $150^{\circ} \mathrm{E}$, within the meridional range of $3^{\circ}$ centered at the monthly-mean STCC position defined from Fig. 3c. The zonal average suppresses the effect of vigorous mesoscale eddies and isolates the structure of the STCC. Since the meridional position of the STCC is rather stable in time and the STCC is typically situated within $1.5^{\circ}$ in latitude north and south of the mean position, the meridional range used here is adequate to capture the STCC 
variation. Notice that our results are insensitive to the slight change in the meridional range.

Figure 5 shows the correlation coefficients between a month from March to June and all the calendar months. The autocorrelation functions computed from the interannual time series indicate that the dominant temporal scale is almost the same about 6 years. Based on this result, we estimated the degree of freedom and obtained a confidence limit of the correlation. The STCC variations in March to June are significantly correlated with those in January to July, but the correlation rapidly decreases in August to December, indicating that the variations are similar during winter to spring, but different from those during summer to fall.

The interannual variations of the STCC, the SST front, and the wind stress curl were examined for each month. We first calculated the zonal averages of the zonal geostrophic velocity, the magnitude of SST gradient, and the wind stress curl between $135^{\circ}$ and $150^{\circ} \mathrm{E}$ from their monthly mean maps. The interannual standard deviations of these zonal-mean variables were then computed for each month from the monthly meridional profiles. The result is shown in Fig. 6.

The variance of the wind stress curl shows a local peak in the area of climatological cyclonic wind curls in April and May, which is almost coincident with the high variance of the SST gradient (Fig. 5a, b). This collocation indicates a local interaction between the SST front and the surface wind, though the high variance of the SST gradient occurs to the south of the mean position of the SST front. The zonal velocity shows high variance at $21^{\circ}-22^{\circ} \mathrm{N}$ on the south flank of the northern STCC from June to September when the STCC is maintained by the subsurface STF.

To explore the local interaction between the SST front and surface wind, we calculated the interannual correlation coefficients between the wind stress curl in May and the SST gradient magnitude, SST anomaly, and SSH anomaly for each month (Fig. 7). The calculation was done at each latitude based on the monthly zonal averages in $135^{\circ}$ and $150^{\circ} \mathrm{E}$. To highlight signals associated with the narrow band of the STCC, a meridional high-pass filter is applied to SST and $\mathrm{SSH}$ anomalies by removing an $8^{\circ}$ moving average as the background state. The correlation 
coefficients were computed for the SSH anomaly from 1993 to 2008 and for the other variables from 1982 to 2008, and their statistical significance levels were calculated based on the degrees of freedom determined from the dominant temporal scale of the STCC variations in spring.

In the band of cyclonic wind curls centered at $25^{\circ} \mathrm{N}$ in the May climatology, the interannual anomalies of SST and SSH show significant negative correlation, while the SST gradient has positive correlation (slightly to the south of the negative SST correlation). This result means that strong (weak) cyclonic wind curl is concurrent with the fall (rise) in SST and SSH below and intensified (weakened) SST front to the south. The negative correlation with the SSH anomalies persists through June along the northern flank of the strong STCC at $23.5^{\circ} \mathrm{N}$ in May to June (Fig. $3 c)$.

The lag correlation implies causality, as has been discussed in many studies (e.g., Frankignoul 1985). The correlations between the wind curl and the SST gradient and the SSH anomaly reach a peak in May with zero lag (Fig. 7), indicating that their variations are coupled. In addition, the correlations remain high and marginally significant along $24^{\circ}-25^{\circ} \mathrm{N}$ with the SST gradient and the SSH anomaly leading from late winter. This suggests that the May wind stress curl is induced to some degree by the SST front and STCC in the preceding late winter to early spring, though the mechanism is not clear. We will discuss these results in Section 5.

Figure 8 shows time series of the mean wind stress curl and SST gradient in May and the May-to-June mean SSH anomaly averaged in the area of $24^{\circ}-26^{\circ} \mathrm{N}$ and $135^{\circ}-150^{\circ} \mathrm{E}$. To see the relation with the STCC, the May-to-June mean zonal velocity averaged in the south area of the cyclonic wind anomaly, in $22^{\circ}-25^{\circ} \mathrm{N}$ and $135^{\circ}-150^{\circ} \mathrm{E}$, are also calculated. In support of Fig. 7 , the wind curl changes almost in synchronization with the SST gradient and the SSH. The SSH is negatively correlated with the zonal velocity of the STCC, indicating that the fall (rise) in the SSH results in the strong (weak) STCC to the south by geostrophic balance.

The interannual variations in Fig. 8 are consistent with satellite observations. Using surface 
wind velocity measured by the QuikSCAT scatterometer and SST by the Tropical Rainfall Measuring Mission (TRMM) satellite's Microwave Imager (TMI) from 2000 to 2008, we obtained significant correlation at $95 \%$ confidence limit between the SST gradient and the wind stress curl at 0.69 .

To examine how ocean structure changes in response to the cyclonic wind stress anomaly, we analyzed the Argo profiling float data. The Argo data has increased in number and spatial coverage in the STCC region since 2005. Focusing on the two characteristic years of 2005 with strong cyclonic wind anomaly and 2006 with weak cyclonic anomaly (Fig. 8), we calculated the mean vertical profiles of potential temperature from the observations in May and June in the area of $24^{\circ}-26^{\circ} \mathrm{N}$ and $135^{\circ}-150^{\circ} \mathrm{E}$ where the significant correlation between the wind curl and the SSH anomaly is seen in Fig. 7. Figure 9a compares 2005 and 2006 when the cyclonic wind curls are strong and weak, respectively. There were 13 profiles for 2005, and 32 for 2006.

Compared with the composite profile in 2006 , the temperature decreases overall and the isotherms are lifted upward in 2005. The difference in depth of isotherms between the two years is shown in Fig. $9 \mathrm{~b}$. The isotherms are elevated by about $50 \mathrm{~m}$ between $7^{\circ}$ and $17^{\circ} \mathrm{C}$ in the lower main thermocline (Fig. 9a). This rise of the thermocline simultaneously with the cyclonic wind stress curl is indicative of enhanced Ekman suction. For comparison, the same analysis was done for the areas south and north of the cyclonic wind anomaly between $21.5^{\circ}-23.5^{\circ} \mathrm{N}$ and $26.5^{\circ}-28.5^{\circ} \mathrm{N}$ in the same longitude range (not shown). Unlike the area of the cyclonic anomaly, the temperature profiles do not show large differences between the two years, demonstrating that the change in the thermocline is the response to the local wind forcing via Ekman suction.

Argo observations in the STCC region are relatively sparse and the spatial sampling is different between 2005 and 2006. The different sampling could cause apparent differences in the mean temperature profiles in Fig. 9, when the temperature varies in space. To evaluate this effect, an additional analysis was done using the monthly temperature climatology from the World Ocean 
Atlas (WOA) 2005 (Locarnini et al. 2006). The climatological temperature profile at the position of the Argo observation is obtained from the monthly WOA and is subtracted from the Argo temperature profile. Then, the anomaly profiles are averaged in the area, added to the area-mean profile calculated from the WOA. This procedure reduces the difference in the spatial sampling. The result is quantitatively almost the same as Fig. 9 (not shown), corroborating that the difference in the temperature profile between the two years is not due to that in the spatial sampling of Argo observations.

The change in the deep ocean down to the lower thermocline implies that mode water is not involved with the difference in the STCC between 2005 and 2006 springs. As mentioned in Section 1, the mean northern STCC is anchored by the low PV core of the STMW between the upper and lower thermoclines that is advected to the north of the STCC by the Kuroshio recirculation gyre (Kobashi et al. 2006). The STMW is found in Fig. 9a with weak vertical gradients of temperature around $17^{\circ} \mathrm{C}$. As mentioned above, since the difference between the two years appears in the wide range of temperature, it seems unlikely that the change in the STMW causes the STCC difference between the two years.

The influence of the STMW on the spring STCC is examined using the Argo gridded dataset from the MOAA GPV during 2001 to 2008. The zonal velocity of the STCC from the MOAA GPV is similar to that from the satellite observations in variability (not shown). The layer thickness in the typical density range of the STMW $\left(1025.0-1025.7 \mathrm{~kg} / \mathrm{m}^{3}\right)$ was computed at each grid from the monthly data, and was zonally averaged between $135^{\circ}$ and $150^{\circ} \mathrm{E}$. Figure 10 depicts the meridional profiles of the May-June mean STMW thickness, together with the area-averaged zonal velocity in Fig. 8c to compare with the STCC changes.

The thick STMW appears around $30.5^{\circ} \mathrm{N}$. The change in the STMW is characterized by a gradual thickening from 2001 to 2006, consistent with the result of Qiu and Chen (2006), and likely related to the dynamic state of the Kuroshio Extension. There is no evidence that the 
southward intrusion of thick STMW is coincident with the intensification of the STCC velocity, indicating no connection of the STMW with the interannual variations of the spring STCC. This 8-year result, however, cannot rule out a connection between the mode water and the STCC on decadal timescales, as suggested by the model study of Yamanaka et al. (2008). Since the STMW fluctuates dominantly on decadal timescales (Yasuda and Hanawa 1997; Qiu and Chen 2006; Sugimoto and Hanawa 2010), longer observations are required to assess the influence of the STMW on the STCC. Indeed in an analysis of an eddy-resolving ocean GCM hindcast, Nonaka et al. (2011) showed that mode-water variability is important for STCC on decadal timescales and has a weaker but still discernible effect on interannual variations in STCC.

\section{Summary and discussion}

The present study has used observations from satellites and Argo profiling floats and an atmospheric reanalysis to investigate seasonal and interannual variations of the STCC in the western North Pacific. The satellite altimeter data confirm the two bands of the STCC, consistent with hydrographic observations. The present study focuses on the northern STCC in the latitude range of $20^{\circ}-26^{\circ} \mathrm{N}$. The STCC has a clear seasonal cycle. It is strong in late winter to spring (March to June) with a peak in June, and weak in fall. The SST front that forms in the mixed layer appears along the STCC in January to April, contributing to the strong STCC in March to April. In May to June, while the surface front moves northward, the STCC is slightly shifted to the south. For these months, the STCC is maintained by the enhanced subsurface STF.

The SST front induces weak cyclonic wind curls to the north of the STCC in May. The correlation analysis for interannual variations reveals that the strong (weak) cyclonic wind anomaly causes the SST and SSH to fall (rise), accelerating (decelerating) the STCC to the south by geostrophic balance. The changes in the ocean have a deep vertical structure down to the lower 
thermocline. The thermocline is lifted upward locally in the presence of the cyclonic wind curl, indicative of enhanced Ekman suction. The Ekman suction increases the meridional tilt of the thermocline, accelerating the STCC to the south. Thus, the local wind forcing in May is a major factor for interannual variations in the spring STCC.

These results indicate that in May the ocean affects the atmosphere, which then in turn affects the ocean. Why does such ocean-atmosphere interaction occur in May? First, we address why the cyclonic wind anomaly forms in May. This issue was discussed by Kobashi et al. (2008), who suggested that a strong SST front and high SST in May (Fig. 3a) both favor the generation of the cyclonic wind anomaly.

Why does the cyclonic wind anomaly in May exert a significant influence on the STCC? Using a 1.5 layer reduced-gravity model, the baroclinic ocean response to surface wind forcing is expressed by the linear vorticity equation,

$$
\frac{\partial h}{\partial t}=-\frac{g^{\prime}}{g} w_{e}
$$

where $h$ is the SSH, and $g^{\prime}$ the reduced gravity. Ekman pumping velocity $w_{e}$ is defined by $w_{e}=\operatorname{curl}_{z}(\tau / f) / \rho_{0}$, where $\tau$ is the wind stress vector, $f$ the Coriolis parameter and $\rho_{0}$ the reference density. Here the dissipation and SSH propagation due to Rossby waves are omitted for simplicity. Taking the meridional derivative and applying the geostrophic relation yield,

$$
\frac{\partial u}{\partial t}=\frac{g^{\prime}}{f} \frac{\partial w_{e}}{\partial y}
$$

where $u$ is the surface zonal geostrophic velocity. The equation indicates that positive meridional gradient of Ekman pumping velocity leads to an increase in surface eastward velocity. Using the monthly climatology of wind stress data from QuikSCAT observations, we calculated the mean gradient of Ekman pumping velocity for each month averaged in the STCC region of $20^{\circ}-25^{\circ} \mathrm{N}$, $135^{\circ}-150^{\circ} \mathrm{E}$. The result is shown in Fig. 11. Except in April and May, the meridional gradient of 
Ekman pumping is nearly zero or negative, because the STCC is usually situated along the southern flank of the bowl structure of negative Ekman pumping velocity in the subtropical gyre, as inferred from the wind stress curl distribution in Fig. 3b. This indicates that the Ekman pumping forcing acts to weaken the STCC, against which the STCC is maintained by mode water. In April and May, however, the meridional gradient of Ekman pumping changes to be positive as a zonal band of cyclonic wind curls forms to the north of the STCC, causing a subsequent intensification of the STCC in late spring. Thus, the cyclonic wind anomaly in spring has an important effect on the STCC. The same result is also obtained from JRA-25 wind stress, though the magnitude of the meridional gradient is smaller compared to satellite observations because of the coarse resolution of the reanalysis. Note that substituting a typical value of $g^{\prime}=0.04 \mathrm{~m} / \mathrm{s}^{2}$ in the STCC region in May into the equation (3) gives rise to the change of eastward velocity about $0.5 \mathrm{~cm} / \mathrm{s}$ for one month in May, which is on the same order of magnitude as the actual change in the STCC velocity, about $0.7 \mathrm{~cm} / \mathrm{s}$ as estimated from monthly change in surface velocity in spring averaged in the area of the STCC with eastward velocity in Fig. 3c.

The wind stress curl and SST gradient exhibit large interannual variability in May and are positively correlated with each other, suggesting a positive feedback of the local interaction between the surface wind and the SST front. The cyclonic wind anomaly lowers the SST below and enhances the SST front to the south. The enhanced SST front intensifies the baroclinicity of the lower atmosphere, energizing subsynoptic lows and resulting in the formation of the band of cyclonic wind anomaly (Kobashi et al. 2008).

The lag correlation analysis suggests that the May wind stress curl is affected by the preceding SST front and STCC in late winter to early spring. In these seasons, the SST front makes a large contribution to the strength of STCC. Interannual variations in meridional SST gradient and surface zonal velocity are negatively correlated along the mean position of the STCC at -0.61 and -0.74 for February and March, respectively, indicating that the STCC velocity in late 
winter is affected by the SST front. The strong SST front and STCC in late winter possibly gives favorable conditions for the development of strong SST front in spring, which induces the formation of cyclonic wind anomaly and results in the subsequent variations of the STCC in spring. Indeed, the STCC variations in spring and winter are highly correlated (Fig. 5). Further analysis will be needed to clarify the mechanism of how the atmosphere in spring is affected by the preceding SST front.

What regulates the interannual variations of the SST front in late winter? In the subtropical gyre, with the westerlies to the north and the northeast trade winds to the south, the Ekman convergence is considered an important process for the changes in the surface front along the STCC (Kazmin and Rienecker 1996; Dinniman and Rienecker, 1999). Indeed, Qiu and Chen (2010) found the correlation between interannual changes in the mesoscale eddy activity in the STCC region and the meridional Ekman convergence. In the STCC region, because the mesoscale eddies are due to baroclinic instability of the STCC in late winter (Qiu 1999; Kobashi and Kawamura 2002), the interannual change in the eddy activity is considered to represent the STCC strength in late winter.

We examined the relation between the meridional Ekman convergence and the late winter SST front. Following Nakamura and Kazmin (2003) and Qiu and Chen (2010), the interannual changes in the meridional SST gradient, $G \equiv-\partial T / \partial y$, are related to the meridional Ekman convergence, as expressed by

$$
\frac{\partial G}{\partial t} \approx-\frac{\partial}{\partial y}\left(V_{E} \cdot G\right)
$$

where $V_{E}=-\tau_{x} / \rho f h$ is the meridional Ekman velocity, $\tau_{x}$ is the zonal wind stress, $\rho$ is the reference density, $f$ is the Coriolis parameter, and $h$ is the depth of the surface mixed layer. Here we have neglected zonal variations and vertical advection/mixing. This is rewritten in the integral form as follows, 


$$
G \approx \int_{t_{1}}^{t_{2}}-\frac{\partial}{\partial y}\left(V_{E} \cdot G\right) d t
$$

$V_{E} \cdot G$ was calculated for each month during 1982 to 2008 using JRA-25 wind stress and NOAA SST data and the monthly-mean climatology of the MLD (Ohno et al. 2009), and then was averaged in the SST front region of $24^{\circ}-26^{\circ} \mathrm{N}, 135^{\circ}-150^{\circ} \mathrm{E}$. The integrated Ekman convergence was computed for February and March by setting $t_{2}$ to be February or March and $t_{1}$ from previous October to $t_{2}$. The correlation coefficients between the interannual variations of $G$ and the integrated Ekman convergence in February/March are shown in Fig. 12. The statistical significance of the correlation was estimated from the degrees of freedom based on the dominant temporal scale of $G$. The SST gradient in February shows a significant correlation at 95\% confidence limit with the Ekman convergence integrated from January to February (the correlation coefficient is 0.59 ). The SST gradient in March shows a weak but positive correlation with the integrated Ekman convergence during winter. These results suggest that the winter Ekman convergence affects the interannual changes in the SST front in February and March. However, the comparison of the interannual variances shows that the winter Ekman convergence explains only at most $10 \%$ of the variance of the SST front. We need further investigation to clarify the mechanism of the interannual variations of the SST front in late winter.

Our results suggest the following mechanism for interannual STCC variations (Fig. 13). The SST front and thereby the STCC in late winter affects the subsequent development of the cyclonic wind anomaly in spring. The strong (weak) cyclonic wind anomaly enhances (weakens) the Ekman suction and elevates (depresses) the thermocline below, accelerating (decelerating) the STCC to the south. Since the strong Ekman suction acts to enhance the SST front, the positive feedback between the wind curl and the SST front is suggested to occur in spring.

The cyclonic wind curl anomaly in the STCC region was first reported about 40 years ago by Yoshida and Kidokoro (1967a, b) from an analysis of historical ship-based wind charts. They 
considered that this cyclonic wind drives the mean STCC. However, it proved to be the other way around, with the SST front actually causing the cyclonic wind anomaly. Although the cyclonic wind anomaly is not important for the formation of the mean STCC (Takeuchi 1984), the present study indicates that it is a major factor for interannual variations of the spring STCC.

The interannual variations of the STCC are different between winter to spring and summer to fall (Fig. 5). The present study reveals that the variations in May to June are coupled to the wind stress curl and are affected by the preceding STCC in late winter. By contrast, the STCC in summer to fall shows no correlation with that in winter and spring, suggestive of other mechanisms. The STCC in these seasons is not so strong but exhibits large interannual variability (Fig. 6). We examined but found no relationship to STMW (not shown). Since the eddy activity is high in the STCC region especially in spring, eddy-mean current interaction could be one possible mechanism for the STCC variations in summer to fall.

White et al. (1978) suggested from an analysis of temperature data during 1954 to 1974 that the annual-mean STCC tends to be strong in El Nino years. We examined the relation between the STCC in spring and El Nino Southern Oscillation (ENSO), by calculating the lag correlations between the May-June mean zonal velocity of the STCC in Fig. 8c and the monthly climate indices in each month from previous May to May of the Southern Oscillation index (SOI) and the Nino3 index. These indices are obtained from the JMA website and are smoothed with a 5-month running mean. The maximum correlation coefficients with the SOI and Nino3 are 0.21 and 0.30 , respectively, neither insignificant. Significant correlation was not found between the wind stress curl in the STCC region (Fig. 8a) and the climate indices. These results demonstrate that interannual variations of the spring STCC are induced by the local wind changes rather than by the large-scale circulation changes associated with the ENSO.

Finally, we examine the influence of the cyclonic wind stress anomaly in May on the STCC seasonal cycle. Figure 14 shows the composite profiles of the zonal velocity zonally averaged in 
the same area as in Fig. 3c, for the years of strong and weak cyclonic wind anomaly. The strong and weak years were defined as those when the wind curl time series exceeds plus and minus one standard deviation, respectively. In the strong cyclonic wind years, the STCC remains kept as a narrow and sharp band of the eastward flow all a year around, and the seasonal cycle is clearly identified with a maximum in spring and a minimum in fall, the same as the mean seasonal cycle in Fig. 3c. In contrast, the STCC is rather blurred and the spring peak disappears in the weak cyclonic curl years. These features strongly suggest that the cyclonic wind anomaly in May is an important factor to form the robust STCC with a clear seasonal cycle.

\section{Acknowledgments}

Constructive comments from anonymous reviewers greatly helped improve the manuscript. This study is partially supported by Grants-in-Aid for Scientific Research of the Ministry of Education, Culture, Sports, Science and Technology, Japan [20740267, 22106007, 23340139]. The altimeter product was produced by Ssalto/Duacs and distributed by AVISO, with support from CNES. The SST dataset was obtained from the NOAA website, the TMI SST and QuikSCAT wind data from the Remote Sensing Systems website, and the JRA-25 data from the JMA website. The Argo profiling float data is obtained from the website (http://ocg.aori.u-tokyo.ac.jp/member/eoka/data/), and the Grid Point Value of the Monthly Objective Analysis using the Argo data (MOAA GPV) from the Japan Agency for Marine-Earth Science and Technology (JAMSTEC) website. IPRC publication XXX and SOEST publication XXX. 


\section{References}

Aoki, Y., T. Suga, and K. Hanawa, 2002: Subsurface subtropical fronts of the North Pacific as inherent boundaries in the ventilated thermocline. J. Phys. Oceanogr., 32, 2299-2311.

Dinniman, M. S., and M. M. Rienecker, 1999: Frontogenesis in the North Pacific oceanic frontal zones: A numerical simulation. J. Phys. Oceanogr., 29, 537- 559.

Frankignoul, C, 1985: Sea surface temperature anomalies, planetary waves and air-sea feedback in the middle latitudes. Rev. of Geophysics., 23, 357-390.

Hosoda, S., T. Ohira, and T. Nakamura, 2008: A monthly mean dataset of global oceanic temperature and salinity derived from Argo float observations. JAMSTEC Rep. Res. Dev., 8, 47-59.

Kazmin, A. S., and M. M. Rienecker, 1996: Variability and frontogenesis in the large-scale oceanic frontal zones. J. Geophys. Res., 101, $907-921$.

Kobashi, F., and A. Kubokawa, 2011: Review on North Pacific Subtropical Countercurrent and Subtropical Front: Role of mode water in ocean circulation and climate. J. Oceanogr., submitted.

Kobashi, F., S.-P. Xie, N. Iwasaka, and T. T. Sakamoto, 2008: Deep atmospheric response to the North Pacific oceanic subtropical front in spring. J. Climate, 21, 5960-5975.

Kobashi, F., H. Mitsudera, and S.-P. Xie, 2006: Three subtropical fronts in the North Pacific: Observational evidence for mode water-induced subsurface frontogenesis. J. Geophys. Res., 111, C09033, doi:10.1029/2006JC003479.

Kobashi, F., and H. Kawamura, 2002: Seasonal variation and instability nature of the North Pacific Subtropical Countercurrent and the Hawaiian Lee Countercurrent. J. Geophys. Res., 107, 3185, doi:10.1029/2001JC001225.

Kubokawa, A., 1999: Ventilated thermocline strongly affected by a deep mixed layer: A theory for subtropical countercurrent. J. Phys. Oceanogr., 29, 1314-1333. 
Kubokawa, A., and T. Inui, 1999: Subtropical countercurrent in an idealized ocean GCM. J. Phys. Oceanogr., 29, 1303-1313.

Locarnini, R. A., A. V. Mishonov, J. I. Antonov, T. P. Boyer, and H. E. Garcia, 2006. World Ocean Atlas 2005, Volume 1: Temperature. S. Levitus, Ed. NOAA Atlas NESDIS 61, U.S. Government Printing Office, Washington, D.C., 182 pp.

Masuzawa, J., 1969: Subtropical mode water. Deep-Sea Res., 16, 436-472.

Nakamura, H., 1996: A pycnostad on the bottom of the ventilated portion in the central subtropical North Pacific: Its distribution and formation. J. Oceanogr., 52, 171-188.

Nakamura, H., and A. S. Kazmin, 2003: Decadal changes in the North Pacific oceanic frontal zones as revealed in ship and satellite observations. J. Geophys. Res., 108, 3078, doi:10.1029/1999JC000085.

Nonaka, M., S.-P. Xie, and H. Sasaki, 2011: Interannual variations in low potential vorticity water and the subtropical countercurrent in an eddy-resolving OGCM. J. Oceanogr., in press.

Ohno, Y., N. Iwasaka, F. Kobashi, and Y. Sato, 2009: Mixed layer depth climatology of the North Pacific based on Argo observations. J. Oceanogr., 65, 1-16.

Oka, E., L. D. Talley, and T. Suga, 2007: Temporal variability of winter mixed layer in the mid- to high-latitude North Pacific. J. Oceanogr., 63, 293-307.

Oka, E., and B. Qiu, 2011: Progress of North Pacific Mode Water Research in the Past Decade. J. Oceanogr., in press.

Onogi, K., J. Tsutsui, H. Koide, M. Sakamoto, S. Kobayashi, H. Hatsushika, T. Matsumoto, N. Yamazaki, H. Kamahori, K. Takahashi, S. Kadokura, K. Wada, K. Kato, R. Oyama, T. Ose, N. Mannoji and R. Taira, 2007: The JRA-25 Reanalysis. J. Meteor. Soc. Japan, 85, 369-432.

Qiu, B., and S. Chen, 2010: Interannual variability of the North Pacific Subtropical Countercurrent and its associated mesoscale eddy field. J. Phys. Oceanogr., 40, 213-225.

Qiu, B., and S. Chen, 2006: Decadal variability in the formation of the North Pacific Subtropical 
Mode Water: Oceanic versus atmospheric control. J. Phys. Oceanogr., 36, 1365-1380.

Qiu, B., 1999: Seasonal eddy field modulation of the North Pacific subtropical countercurrent: TOPEX/Poseidon observations and theory. J. Phys. Oceanogr., 29, 2471-2486.

Reynolds, R. W., T. M. Smith, C. Liu, D. B. Chelton, K. S. Casey and M. G. Schlax, 2007: Daily High-resolution Blended Analyses for sea surface temperature. J. Climate, 20, 5473-5496.

Sasaki, H., S.-P. Xie, B. Taguchi, M. Nonaka, S. Hosoda, and Y. Masumoto, 2011: Interannual variations of the Hawaiian Lee Countercurrent induced by low potential vorticity water ventilation in the subsurface. J. Oceanogr., submitted.

Suga, T., Y. Takei, and K. Hanawa, 1997: Thermostad distribution in the North Pacific subtropical gyre: The central mode water and the subtropical mode water. J. Phys. Oceanogr., 27, $140-152$.

Sugimoto, S., and K. Hanawa, 2010: Impact of Aleutian Low activity on the STMW formation in the Kuroshio recirculation gyre region. Geophys. Res. Lett., 37, L03606, doi:10.1029/2009GL041795.

Takeuchi, K., 1984: Numerical study of the Subtropical Front and the Subtropical Countercurrent. J. Oceanogr. Soc. Japan, 40, 371-381.

Takeuchi, E., and I. Yasuda, 2003: Wintertime shoaling of oceanic surface mixed layer. Geophys. Res. Lett., 30(22), 2152, doi:10.1029/2003GL018511.

Tokinaga, H., S.-P. Xie, F. Kobashi, and Y. Tanimoto, 2009: Local and remote influences of the Kuroshio Extension on the atmosphere. U.S. CLIVAR Variations, 7, 1-4.

Uda, M., and K. Hasunuma, 1969: The eastward subtropical countercurrent in the western North Pacific Ocean. J. Oceanogr. Soc. Japan, 25, 201-210.

White, W. B., K. Hasunuma, and H. Solomon, 1978: Large-scale seasonal and secular variability of the subtropical front in the western North Pacific from 1954 to 1974. J. Geophys. Res., 83, 4531-4544. 
Xie, S.-P., C. Deser, G.A. Vecchi, J. Ma, H. Teng, and A.T. Wittenberg, 2010: Global warming pattern formation: Sea surface temperature and rainfall. J. Climate, 23, 966-986.

Xie, S.-P., L.-X. Xu, Q. Liu, and F. Kobashi, 2011: Dynamical role of mode-water ventilation in decadal variability in the central subtropical gyre of the North Pacific. J. Climate, 24, $1212-1225$

Xu, L.-X., S.-P. Xie, Q. Liu, and F. Kobashi, 2011: Response of the North Pacific subtropical countercurrent and its variability to global warming. J. Oceanogr., in press.

Yamanaka, G., H. Ishizaki, M. Hirabara, and I. Ishikawa, 2008: Decadal variability of the Subtropical Front of the western North Pacific in an eddy-resolving ocean general circulation model. J. Geophys. Res., 113, C12027, doi:10.1029/2008JC005002.

Yasuda, T., and K. Hanawa, 1997: Decadal changes in the mode waters in the midlatitude North Pacific. J. Phys. Oceanogr., 27, 858-870.

Yoshida, K., and T. Kidokoro, 1967a: A subtropical countercurrent in the North Pacific - An eastward flow near the Subtropical Convergence. J. Oceanogr. Soc. Japan, 23, 88-91.

Yoshida, K., and T. Kidokoro, 1967b: A subtropical countercurrent ( II ) - A prediction of eastward flows at lower subtropical latitudes. J. Oceanogr. Soc. Japan, 23, 231-236. 


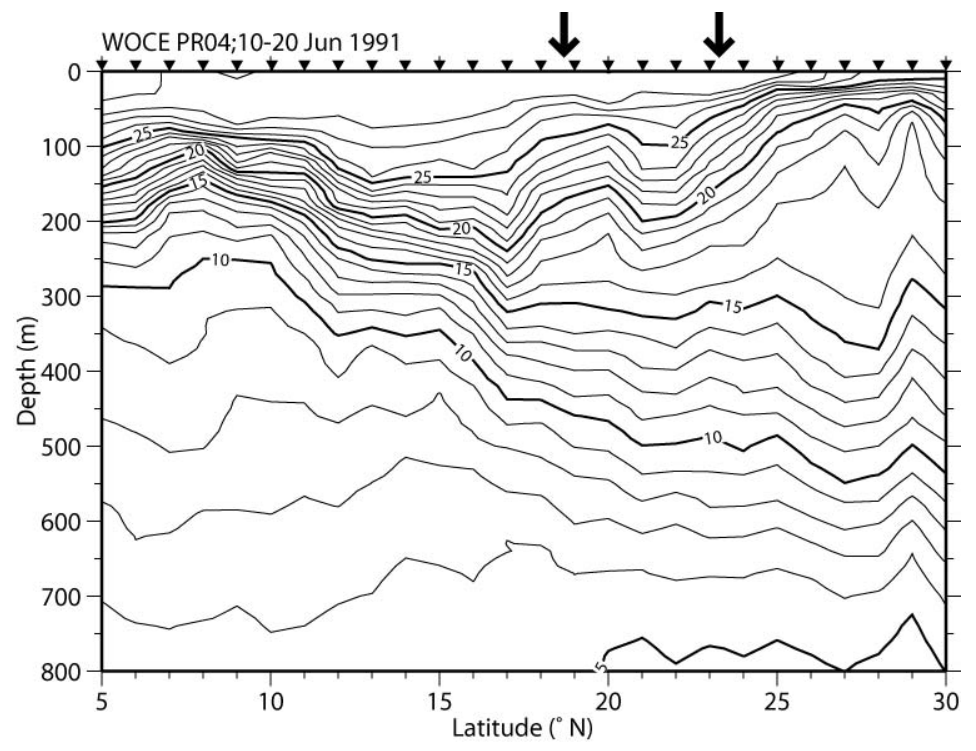

Figure 1: Temperature section along $155^{\circ} \mathrm{E}$, taken by the R/V Ryofu Maru in a WOCE cruise during June 1991. Downward arrows indicate the position of STFs. The location of observation is denoted by inverted triangles. (From Kobashi et al. 2006.) 


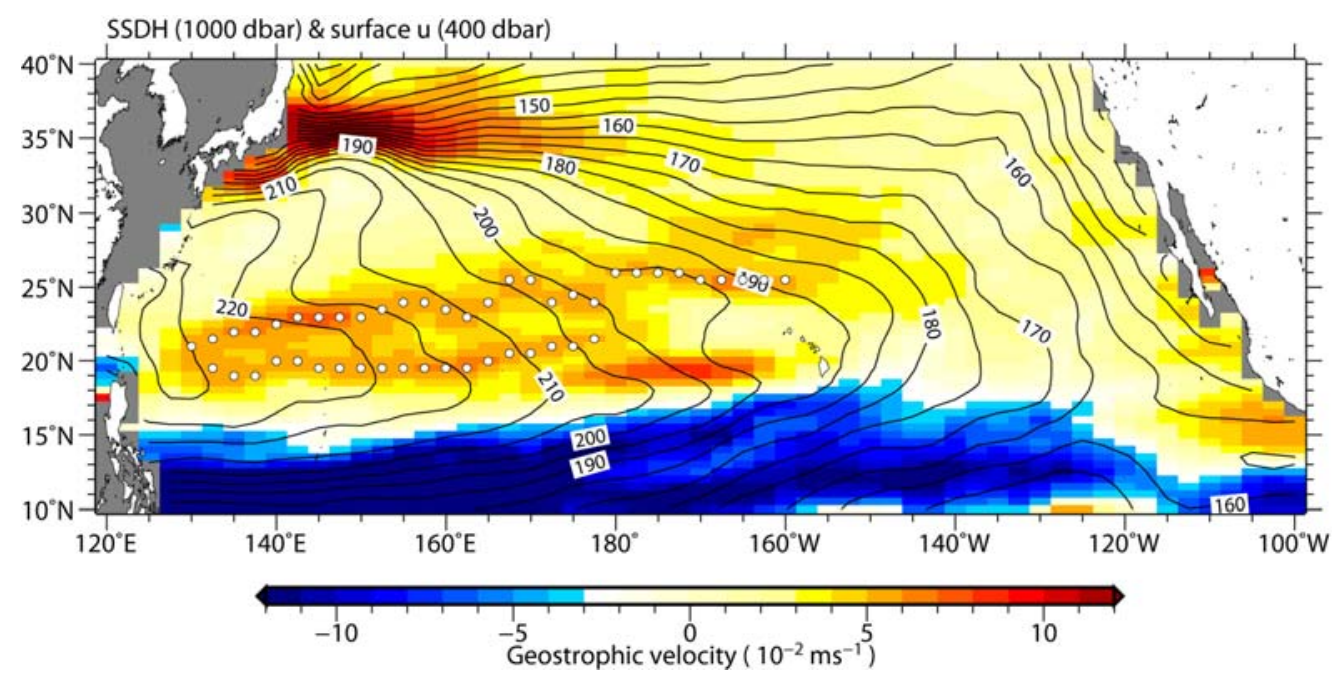

Figure 2: Annual-mean surface zonal geostrophic velocity relative to 400 dbar (color shade), and sea surface dynamic height referenced to $1000 \mathrm{dbar}$ (contours with an interval of $5 \mathrm{~cm}$ ). Since $400 \mathrm{dbar}$ corresponds to mostly the deepest level that STF reaches, the zonal velocity represents the vertically integrated strength of STF. Open circles denote the position of STF and STCC. (From Kobashi et al. 2006.) 
(a) SST \& Meridional SST gradient

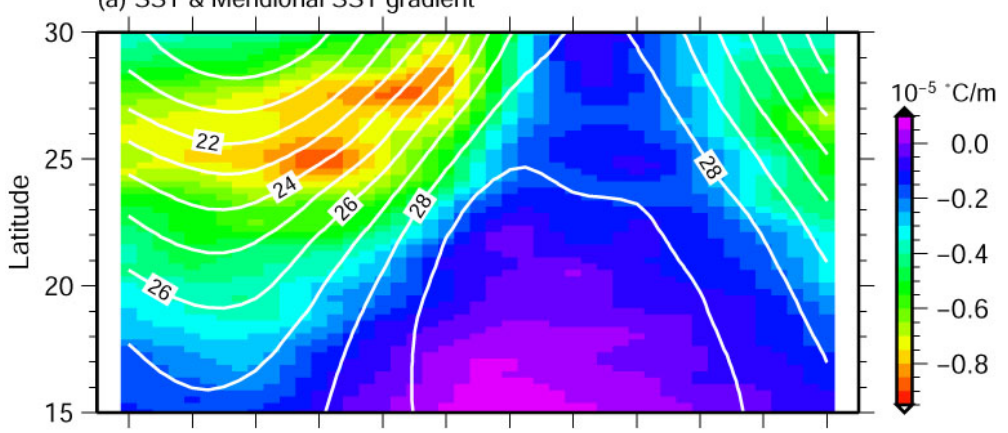

(b) Wind stress \& wind stress curl

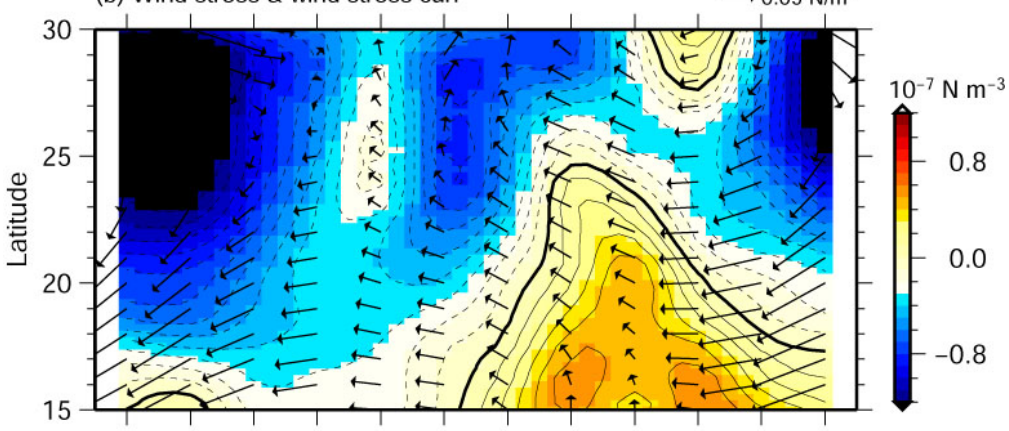

(c) Surface geostrophic velocity \& zonal velocity

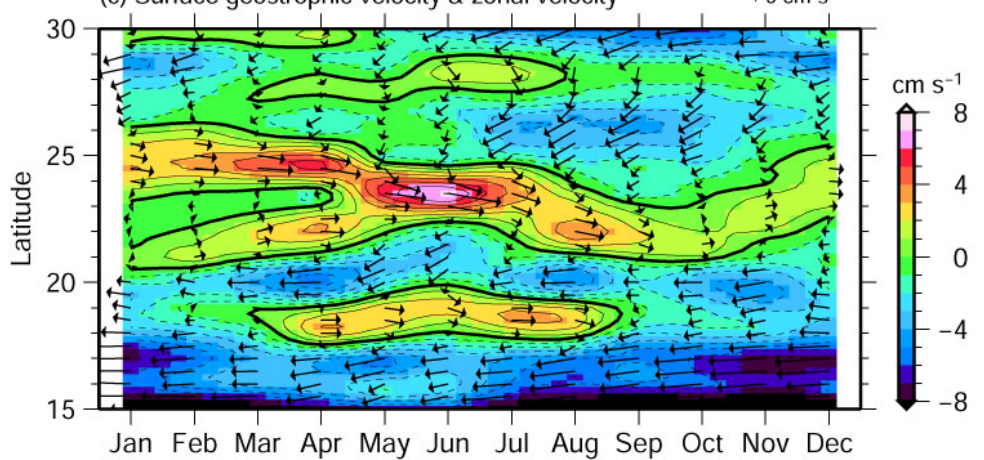

Figure 3: Mean seasonal cycle as represented in time-latitude sections of (a) SST (thick contours) and meridional SST gradient (color shade), (b) vector wind stress and wind stress curl (color shade), and (c) surface geostrophic velocity vector and zonal velocity (color shade), zonally averaged between $135^{\circ}$ and $150^{\circ} \mathrm{E}$. 


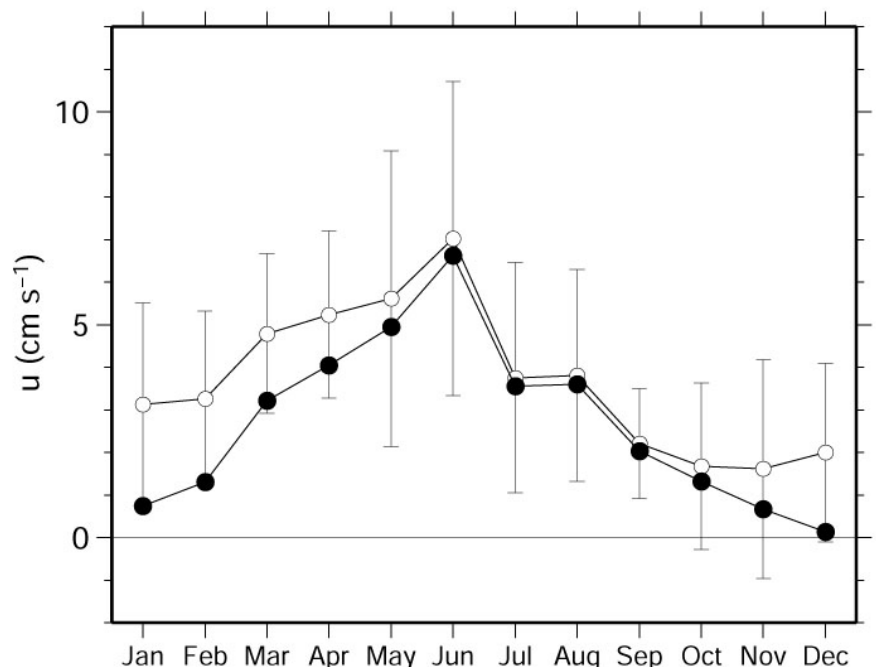

Figure 4: Monthly-mean zonal geostrophic velocity of the STCC extracted as a meridional maximum between $20^{\circ}$ and $26^{\circ} \mathrm{N}$ from the zonally-averaged profiles in Fig. 3c (open circle). Error bars denote $90 \%$ confidence interval of the zonal mean. The zonal velocity minus the vertical shear within the surface mixed layer (filled circle) represents the subsurface front effect. 


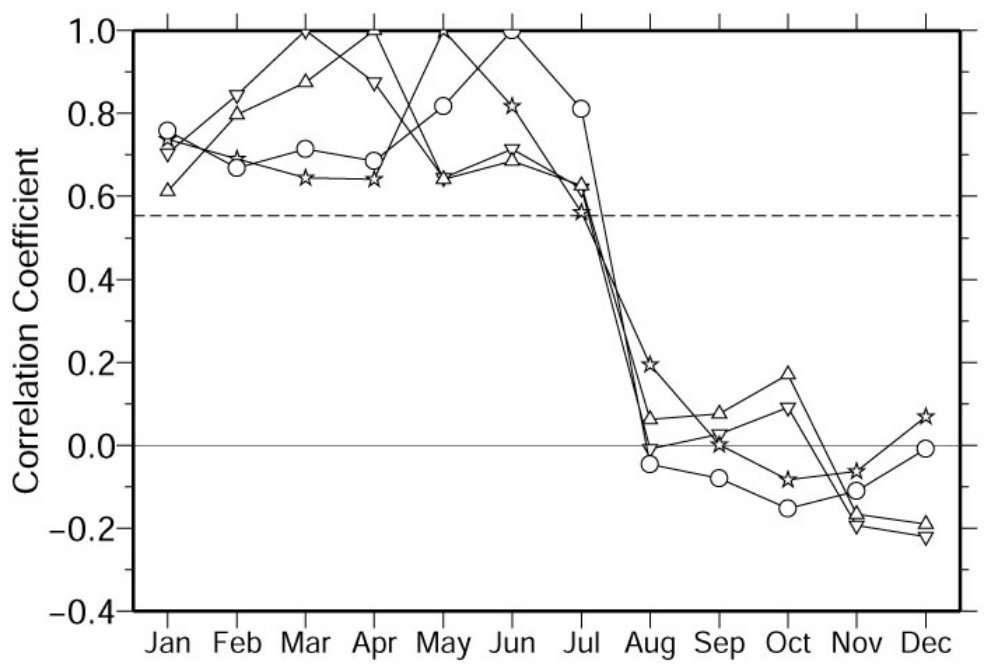

Figure 5: Correlation coefficients of the interannual variations between the zonal velocity of the STCC in March (inverted triangle), April (triangle), May (star) and June (circle) and in the other months. See the text for details. Correlation exceeding the dotted line is significant at the $95 \%$ confidence limit $(>0.55)$. 

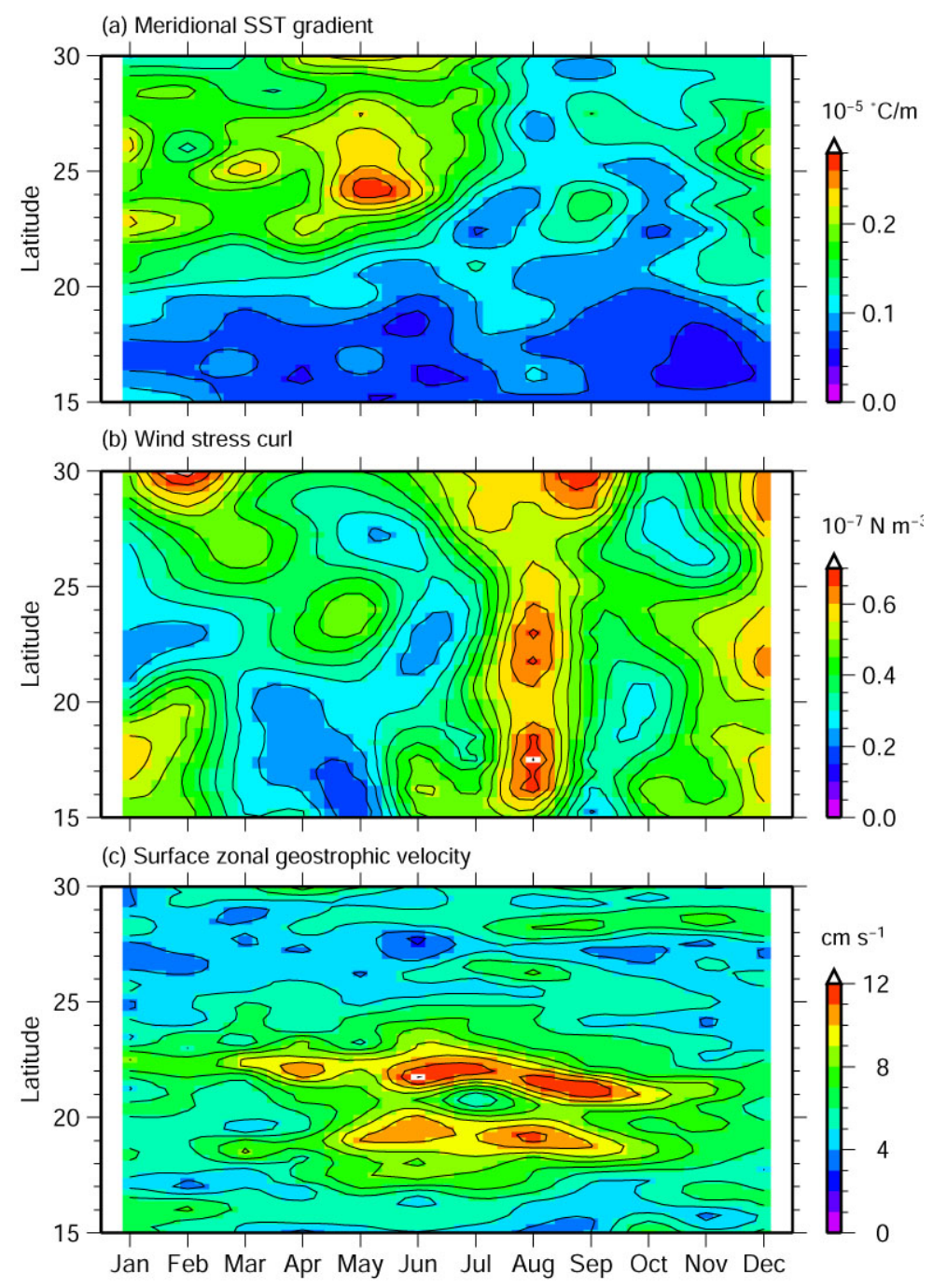

Figure 6: Monthly distribution of the interannual standard deviations of (a) meridional SST gradient, (b) wind stress curl, and (c) surface zonal geostrophic velocity, calculated from the monthly-mean meridional profiles zonally averaged between $135^{\circ}$ and $150^{\circ} \mathrm{E}$. 

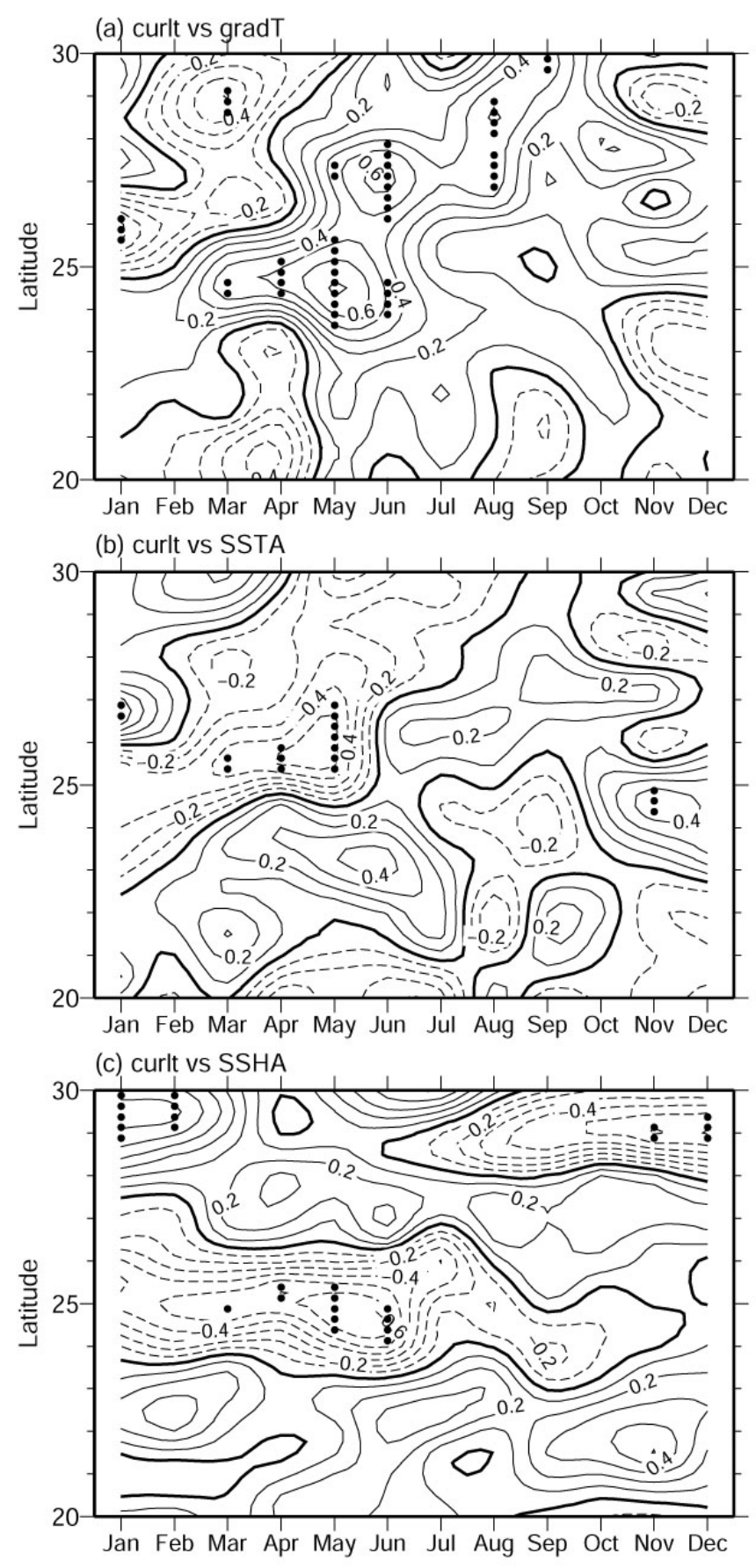

Figure 7: Correlation coefficients of the interannual variations between the wind stress curl in May and (a) the magnitude of SST gradient, (b) SST anomaly, and (c) SSH anomaly in the other months, calculated at each latitude using the monthly-mean meridional profiles zonally averaged between $135^{\circ}$ and $150^{\circ} \mathrm{E}$. Grid points of significant correlation at the $95 \%$ confidence limit are denoted by black dots. 
(a) SST gradient (dashed) and curlt (solid)

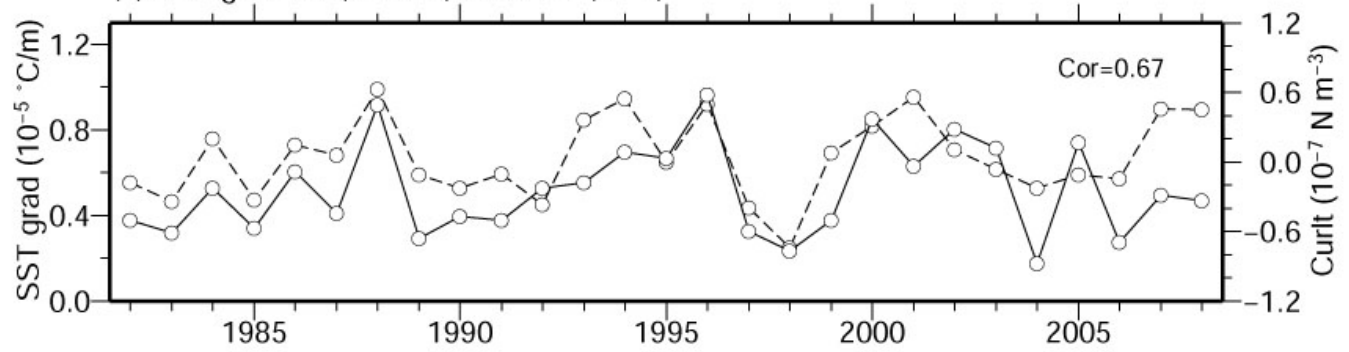

(b) Curlt (solid) and -SSHA (dashed)

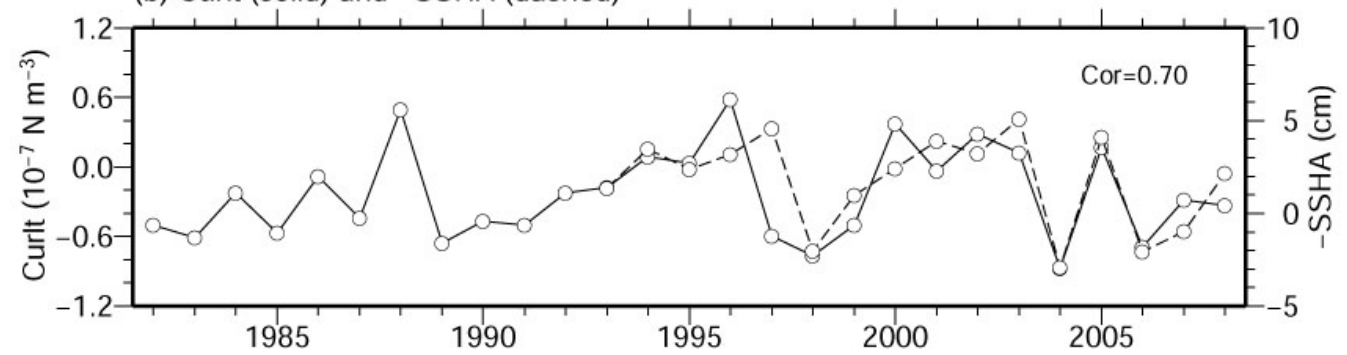

(c) -SSHA (dashed) and zonal velocity (solid)

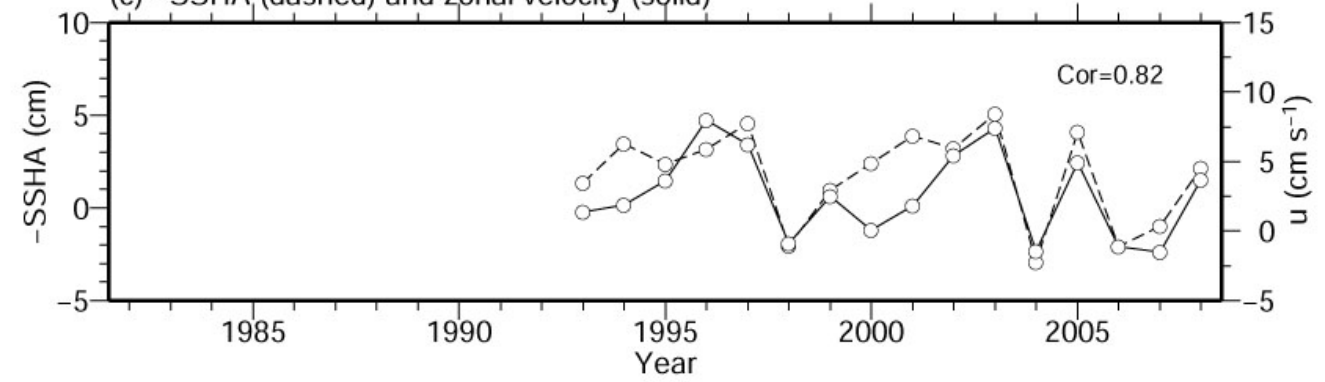

Figure 8: Time series of May-mean wind stress curl and SST gradient and the May-to-June mean SSH anomaly averaged in the area of $24^{\circ}-26^{\circ} \mathrm{N}$ and $135^{\circ}-150^{\circ} \mathrm{E}$, and the May-to-June mean zonal geostrophic velocity of the STCC averaged in $22^{\circ}-25^{\circ} \mathrm{N}$ and $135^{\circ}-150^{\circ} \mathrm{E}$. The SST gradient is shown by a dashed line in (a), the wind stress curl by a solid line in (a) and (b), the SSH anomaly by a dashed line in (b) and (c), the zonal velocity by a solid line in (c). For easy comparison, the SSH anomaly is multiplied by a minus. 

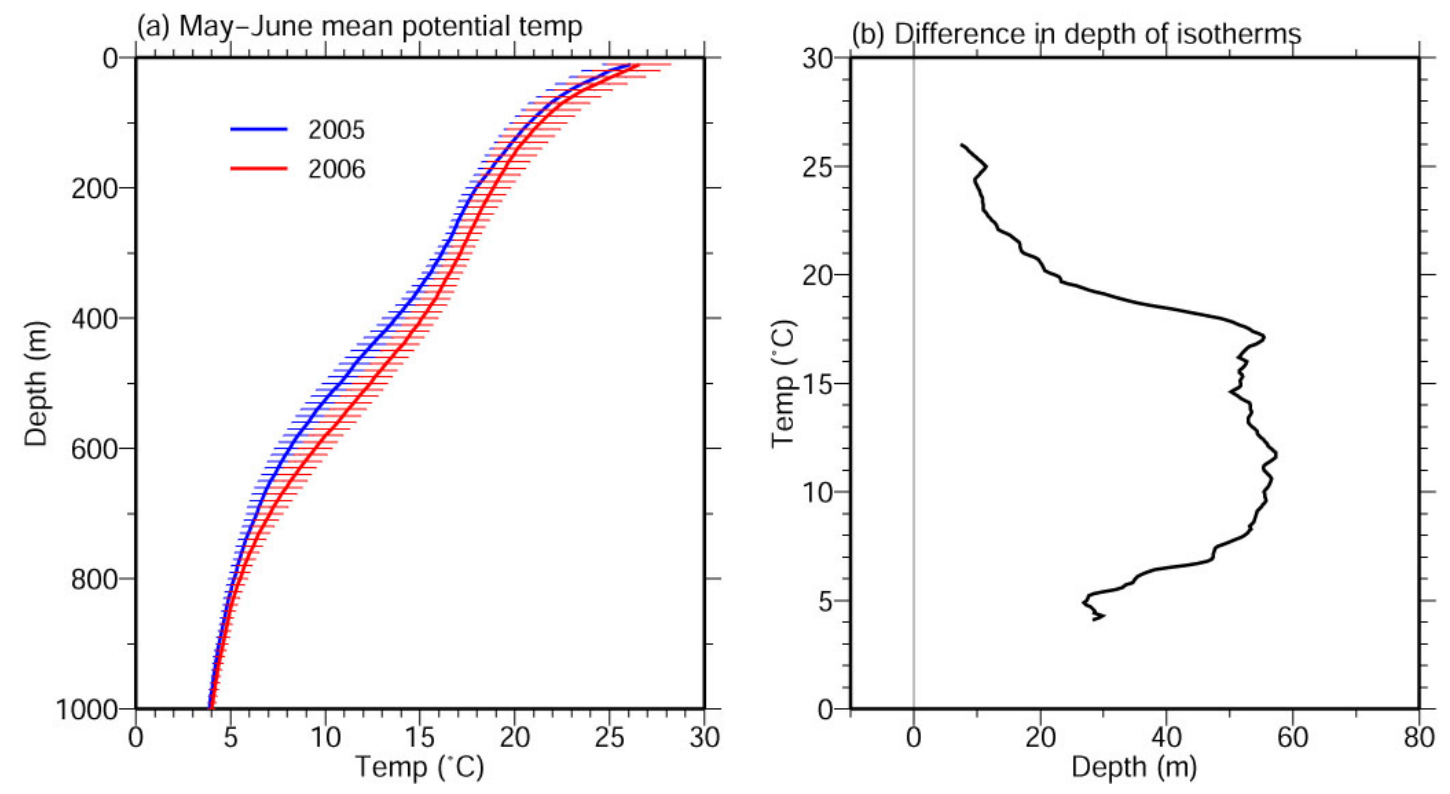

Figure 9: (a) Mean vertical profiles of potential temperature in 2005 and 2006 together with the standard deviation of the mean, calculated from the Argo profiling floats in May and June in the area of $24^{\circ}-26^{\circ} \mathrm{N}$ and $135^{\circ}-150^{\circ} \mathrm{E}$. (b) Difference in depth of isotherms between 2005 and 2006. The number of the profiles used is 13 for 2005 and 32 for 2006. 
(a) STMW thickness (m) (25.0-25.7 $\left.\sigma_{\theta}, 135-150 E\right)$
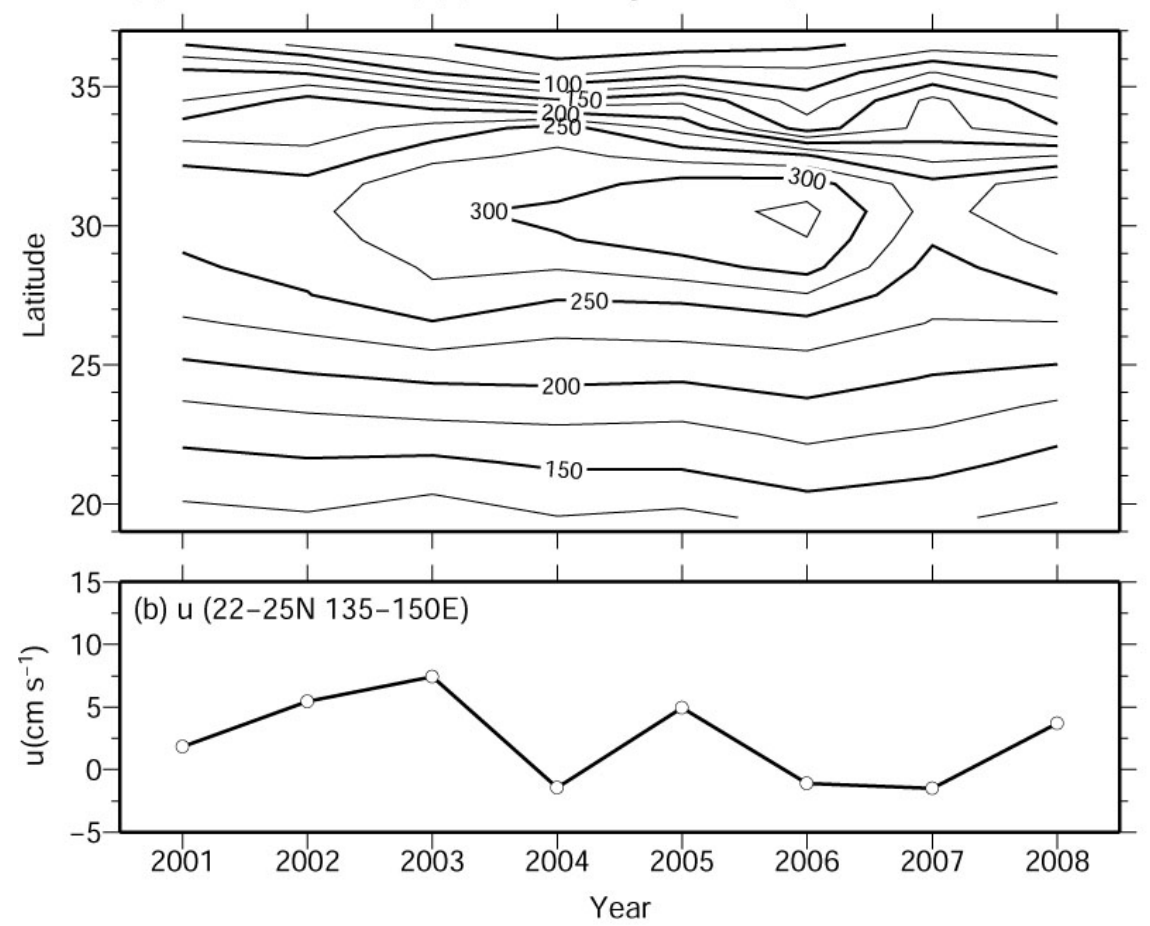

Figure 10: (a) Interannual changes in May-June mean STMW thickness in the density range of $1025.0-1025.7 \mathrm{~kg} / \mathrm{m}^{3}$, zonally averaged between $135^{\circ}$ and $150^{\circ} \mathrm{E}$. (b) Area-averaged zonal velocity of the STCC (the same as Fig. 8c). 


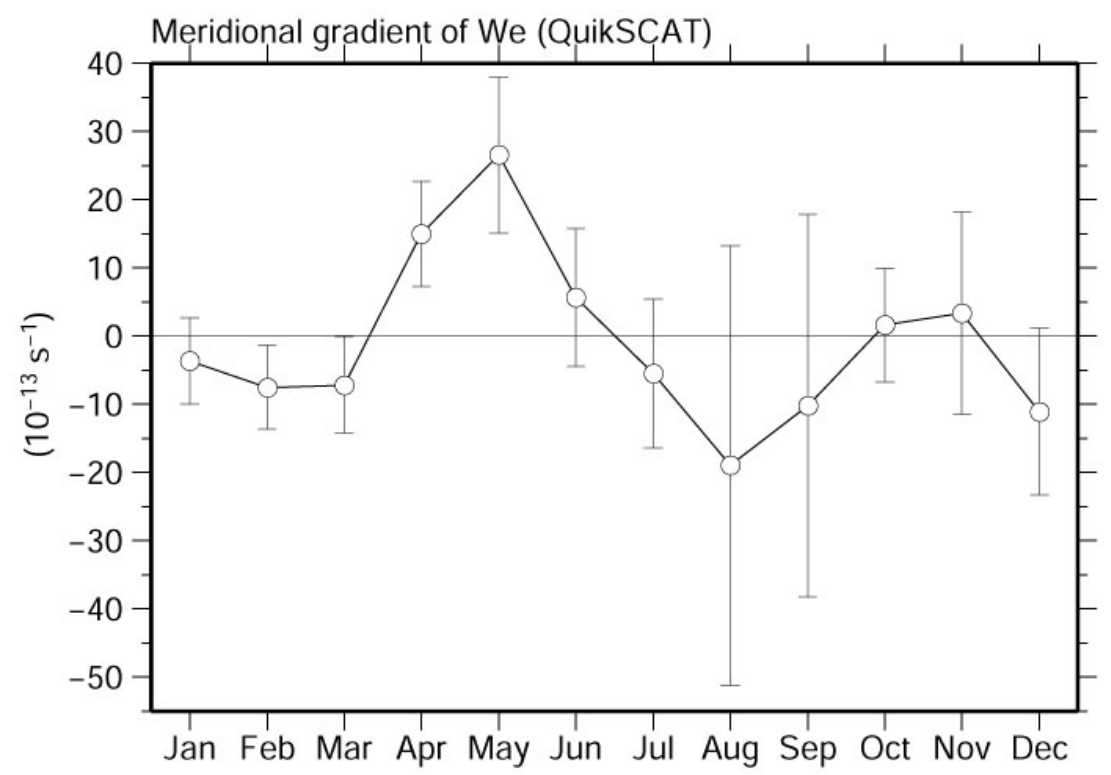

Figure 11: Monthly-mean meridional gradients of Ekman pumping velocity in the STCC area of $20^{\circ}-25^{\circ} \mathrm{N}$ and $135^{\circ}-150^{\circ} \mathrm{E}$, calculated from QuikSCAT observations. Error bars denote $95 \%$ confidence interval of the area mean. 


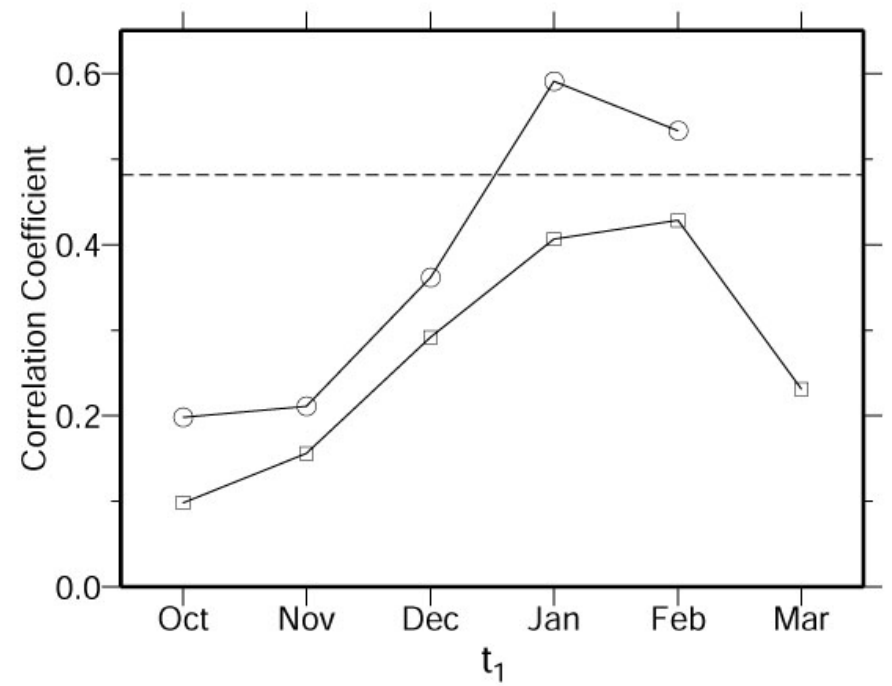

Figure 12: Correlation coefficients between the interannual variations of the meridional SST gradients $(G)$ in February (circle) and March (square) and the meridional Ekman convergence integrated from $t_{1}$ to February (circle) and March (square). See the text for details. Correlation exceeding the dotted line is significant at the $95 \%$ confidence limit. 


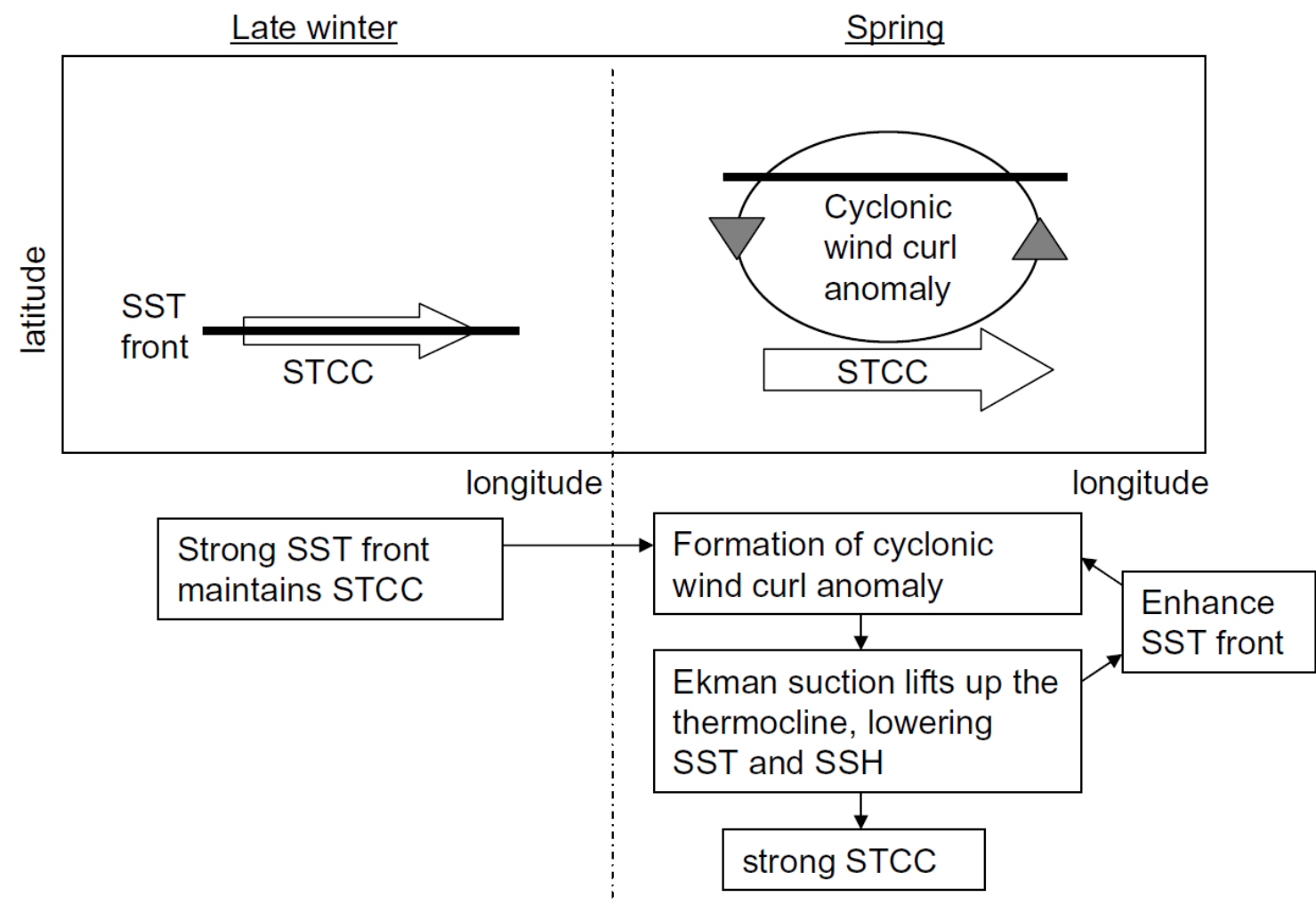

Figure 13: A schematic summary depicting the interannual variations of the STCC (open arrows) and the SST front (thick horizontal lines) related to the cyclonic wind curl (circle) during late winter (left panel) and spring (right panel). See the text for details. 
(a) strong cyclonic curl year

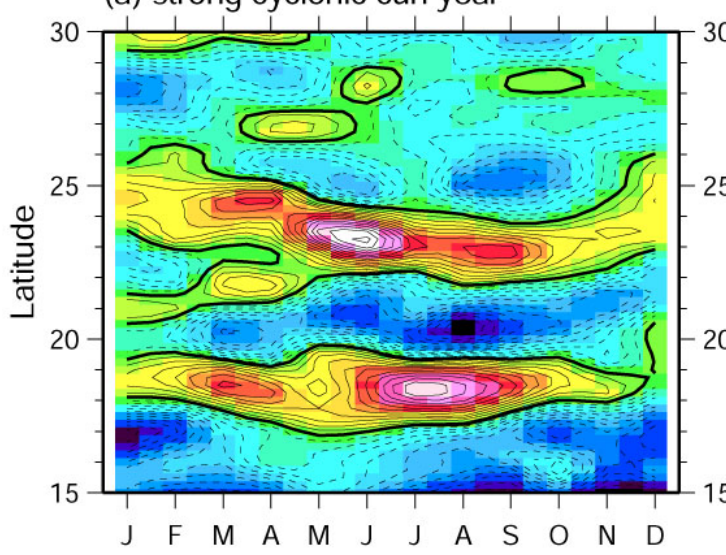

(b) weak cyclonic curl year

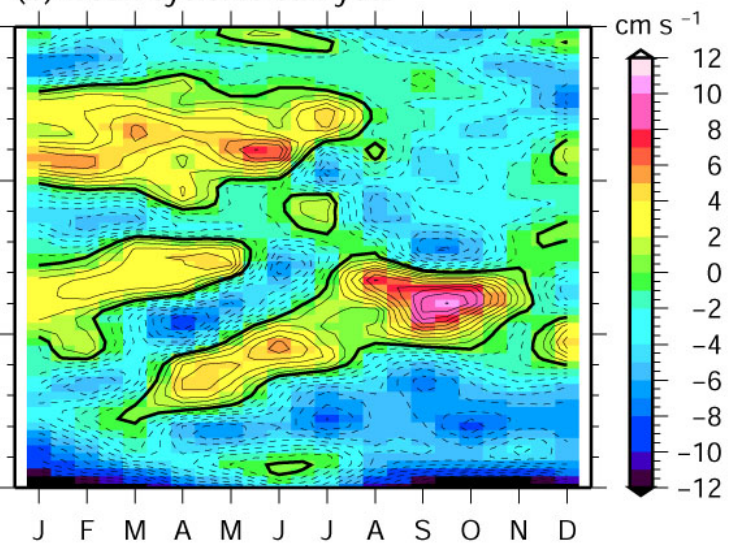

Figure 14: Composite of seasonal cycle of surface zonal geostrophic velocity in (a) strong cyclonic curl years $(1996,2000,2002,2005)$ and (b) weak cyclonic curl years $(1998,2004,2006)$, calculated from the monthly-mean meridional profiles zonally averaged between $135^{\circ}$ and $150^{\circ} \mathrm{E}$. 